and it is evident that the analysis of networks containing reactances varying with time presents many problems, not the least of which is that of determining the conditions for stability.

In the third session Dr. O. P. D. Cutteridge (Manchester College of Science and Technology) spoke on the application of a particular continued-fraction expansion to a range of problems of active and passive networks. The expansion may also be used to determine the character of the zeros of a polynomial.

A lengthy discussion was initiated by a paper on the synthesis of three-terminal resistance-capacitance networks, presented by Mr. J. T. Allanson (University of Birmingham). There exists no complete solution to the problem of designing a network of this kind if the three impedance functions of the network are specified. It can be shown, by analysis of real networks, that the impedance matrix for any three-terminal resistance-capacitance network must necessarily satisfy certain conditions : it can also be shown, by synthesis of notworks, that if an impedance matrix satisfies a more extensive set of conditions a network of this type may be found to represent the matrix. The paper and the discussion were concerned with attempts to close the gap between these two-the necessary and the sufficient-.-sets of conditions.

A discussion of a similar kind took place after Dr. W. Saraga (Siemens Edison Swan, London) had discussed the analysis and synthesis of reactance networks in terms of the 'one-points' of various functions. The traditional methods of analysis and synthesis have regarded the poles and zeros of various network functions as constituting the most easily handled specification of these functions, but there are certain advantages in using the values taken by the complex frequency variable when the functions in question have the values of \pm 1 . However, the simplicity of procedure which results from using these 'one-points' in network synthesis has to be paid for by an increase in the number of network elements required to realize a given set of functions. In practical applications these redundant elements must be removed and the series of network transformations necessary to do this may be sufficiently complicated to nullify the advantages of the preceding simplicity. It appears that 'one-point' analysis may be most use. fully applied as complementary to pole-zero analysis in revealing useful general relations in networks.

Dr. G. S. Brayshaw (University of Leeds) presented a paper dealing with an application of positive-real graphs and Dr. A. Talbot (Imperial College, London) discussed the use of Tchebyscheffian approximations in network synthesis, and outlined an algebraic method for the determination of rational approximating functions suitable for filters required to have Tchebyscheffian characteristics in both pass and stop bands.

In the fourth session of the conference two papers were read on the design and construction of filter networks. Mr. E. R. Austin (Post Office Research Station, London) outlined a computational procedure for obtaining, in the form of a ladder network, an image parameter filter in which advantage is taken of the theoretical possibility of specifying independently the attenuation and impedance characteristics. The design may be regarded as yielding a filter more efficient than the corresponding Zobel type but less so than one designed on an insertion loss basis. Dr. J. H. Mole (H.M. Underwater Detection Establishment, Portland) spoke on problems of component design, accuracy and tolerance, mechanical construction and the testing and measurement of practical filters.

The final session of the conference was taken up with a discussion on the place and teaching of electrical network theory in universities and technical colleges. Mr. F. E. Rogers (The Polytechnic, London), Dr. A. W. Keen (Coventry Technical College), and Mr. E. R. Broad (Post Office Research Station, London) opened the discussion, which was vigorous but inconclusive. However, it was agreed that more attention must be paid to the physical and mathematical fundamentals underlying the practical techniques for the solution of network problems and less time given to these techniques themselves.

J. T. Altanson

\title{
BRITISH OVERSEAS INFORMATION SERVICES
}

$I^{N}$ $\mathrm{N}$ a written statement circulated in reply to a 1 question in the House of Commons on November 16 as to the implementation of the proposals in the White Paper on Overseas Information, the Chancellor of the Duchy of Lancaster, Dr. C. Hill, stated that since April 1, 1959, the British Council has recruited 140 teachers of English for overseas posts, and expenditure on exchanges of university teachers with foreign countries has risen from $£ 6,164$ in 1958-59 to about $£ 9,014$ for $1959-60$; for Commonwealth exchanges the corresponding figures are $£ 12,113$ and £16,113. The number of scholarships awarded by the Council has risen from 284 in 1958-59 to 355 in $1959-60$, and of these 98 and 141 , respectively, were related to the teaching of English, including twelve new scholarships for students from the Colonial territories for teaching English as a second language, 14 studentships at the University of London Institute of Education for United Kingdom graduates intending to teach English overseas, and fifteen new posts concerned with the teaching of English estab- lished overseas. Educational exchanges with Czechoslovakia and Hungary have commenced, including a three-week visit to British universities of six professors from Czechoslovakia. Government grants to the British Council were estimated at $£ 5,824,000$ for 1959-60, compared with $£ 4,615,000$ in 1958-59.

Expenditure on British Council libraries was $£ 234,000$ in $1958-59$ and will rise to about $£ 480,000$; for books and periodicals for presentation, the corresponding figures are $£ 39,000$ and $£ 72,000$. In consultation with the Governments concerned, twenty new British Council libraries have been, or will shortly be, set up, and long-term lending library services for students are now operating or will shortly operate at nine Council centres and through universities. Libraries of the long-lending type are already operating in Karachi, Rawalpindi and Dacea and in process of being extended to Lahore and Chittagong, and first indications are that they are a great success. More than 30,000 books have been sent out and 235 additional subscriptions to periodicals provided for 
Council libraries in India since April 1, 1959 ; for Pakistan, the corresponding figures are nearly 40,000 and 104. Measures to promote exports of British books and periodicals are making good progress, and proposals have been put to the Governments of Indonesia, Israel, Pakistan, Poland and Yugoslavia with the aim of agreeing upon schemes broadly on the lines of the former British book export schemes. Trade organizations in the periodical field have been consulted on measures to assist circulation of newspapers and periodicals in some of the more difficult markets overseas.

In broadcasting, Dr. Hill said that excellent progress has been made with the construction of the new relay transmitter at Berbera, and the Arabic Service of the B.B.C. is now transmitting for $12 \mathrm{hr}$. daily compared with $4.5 \mathrm{hr}$. in 1957. Efforts have been made to increase both the local and general appeal of the Service, and arrangements have been made to provide the local Press and broadcasting services in Fast Africa and Aden with more material on the background in the news. A conference of the Governments of the East African territories, Aden and the Somaliland Protectorate in March 1959 provided a valuable interchange of information and ideas, and the re-appraisal of the Overseas Service of the B.B.C. in English, nearing completion, has given full weight to the special importance of increasing the appeal of these Services to the rapidly growing number of listeners overseas for whom English is a second language. Studies have been made of the possibility of introducing television in Aden.

With regard to official services, a United Kingdom Information Office has been opened in Kampala and premises in Nairobi are being equipped; expenditure on television material for showing overseas is expected to be $£ 138,000$ in 1959-60 compared with $£ 121,000$ in 1958-59, and all the expansions recommended in the Central Office of Information Services have been made or are in progress. These include improvements in the Press and telegraph services, a radio-type service for local broadcasting in Arabic, Somali and Swahili ; the completion of three experimental television films for the British Council on the teaching of English; increased supply of trade and technical periodicals overseas and an expanded programme of overseas visits, especially on the Commonwealth side. A Commonwealth Exhibition, intended as the focal point of 'Commonwealth Weeks' in several major cities, was opened in Liverpool on November 19 The cost of the Overseas Information Services in $1959-60$ is now estimated at about $£ 16 \cdot 5$ million a year, while measures to promote exports of British publications will cost about a further $£ 500,000$ a year.

\section{METALLOGENIC MAPS}

T HE notion and the term metallogenic or metallo. genetic are due to $\mathrm{L}$. de Launay, who in 1900 proposed the terms 'metallogenic provinces' and 'metallogenic epochs'. Respectively, these two terms meant a particular geographical region or a specific geological epoch characterized by a particular assemblage of mineral deposits. The representation of such a province or provinces on the map led to the construction of metallogenic maps. Such a map differs from what is called a 'mineral map'. A mineral map only shows the distribution of one or several mineral deposits, while the aim of a metallogenic map is not only this but also to relate the distribution of such deposits to the geological formations or periods and to the tectonic features of the region. This leads to the discovery of particular areas of distribution or zones of occurrence ; changes in the character of mineral deposits in time; association of certain chemical elements among the deposits, and many other features.

During the past few decades the problem of construction of metallogenie maps of various countries or on an international basis has been discussed. At the International Geological Congress held in Mexico City in 1956 a Sub-Commission for the Metallogenic Map of the World was created. During March-April 1958 this Sub-Committee, as a part of the wider Commission of the Geological Map of the World, met in Paris (Nature, 182, 502; 1958). At this meeting a number of metallogenic maps of difforent countries were shown and discussed and the future programme outlined.

In the U.S.S.R. the problem of metallogenic provinces, epochs and maps were particularly discussed by the late Y. A. Bilibin (1901-52) and S. S. Smirnov (1895-1947), and at the present time this work occupies the forefront of geological research. Valuable contributions to the metallogeny of various ores were recently made by N. S. Shatsky, discussing the manganese ores (Bull. Acad. Sci. U.S.S.R., Ser. Geol., 4,$3 ; 1954$ ), and phosphorite deposits ("Conf. Sed. Rocks, Acad. Sci. U.S.S.R.", 2, 7 ; 1955). The metallogeny of Kazakhstan has been discussed by K. I. Satpaev (Bull. Acad. Sci. C.S.S.R., Ser. Geol., 6,$34 ; 1953$ ) and A. I. Semenov (Soviet Geology, 58, $110 ; 1957)$. The principles of regional metallogenic analysis have been discussed by V. I. Serpukhov (Soviet Geology, 43, 27 ; 1955). The principlos of metallogeny and the construction of metallogenic maps are discussed by E. T. Shatalov (Bull. Acad. Sci. U.S.S.R., Ser. Geol., 9, 37 ; 1958). An attempt at a general metallogenic survey of the territory of the Soviet Union and the construction of a metallogenic map of the U.S.S.R. was made by V.I. Smirnov (Bull. Acad. Sci. U.S.S.R., Ser. Geol., 4, 3; 1959 and Priroda, 4,$17 ; 1959)$. Recently, E. A. Radkevich (Bull. Acad. Sci. U.S.S.R., Ser. Geol., 5, 125 ; 1959) has published a report of the All-Union Metallogenic Conference held in Alma-Ata during December 1958, at which 800 delegates and visitors were present and a number of papers read and discussed. A valuable summary of the work done in the Soviet Union in this field combined with a manual for the preparation of metallogenic maps has been published in book form. It is edited by P. M. Tatarinov, V. G. Grushevoy and G. S. Labazin, and it is entitled "General Principles of a Regional Metallogenic Analysis and of the Methods of Compilation of Metallogenic Maps of Folded Regions", published by "Gosgeoltekhizdat", Moscow, 1957 (150 pages; price $7 \mathrm{r} .20 \mathrm{k}$.). This volume contains seven articles dealing with the general principles of a regional metallogenic analysis, sedimentary and igneous formations, mineral deposits complexes, metallogenic zones and methods of compilation of metallogenis: maps.
S. I. TOMKEIEFF 